\title{
Research on Public Service in Yunnan Frontier of Ethnic Prefectures
}

\author{
Zhihui Wang* \\ Yunnan university of finance and economics \\ Kun Ming, China \\ 328608635@qq.com \\ Yating Pan \\ Yunnan university of finance and economics
}

\author{
Kun Ming, China \\ Yuan Cui \\ Yunnan university of finance and economics \\ Kun Ming, China
}

\begin{abstract}
Based on statistical data of public service in Yunnan 25 frontier of ethnic prefectures, and research fieldworks in Funing, Hekou, Ruili, Mangshi, this research found that, under the financial support from central government and Yunnan local government, a basic social security system has been established in those frontier ethnic places, and compulsory education, public health 、 traffic infrastructure have developed to some extent. But the supply autonomy, and ethnicity is not apparent character during public service provision, economic development is still a key duty for local government. Therefore, this study suggested that, in order to enhance the quality and quantity of public service in frontier of ethnic prefectures, Chinese central government should provide more funding for local public service, make series of priority policies to improve the development of education and public health, and strengthen the cooperation between various local authorities to build a sound social security system.
\end{abstract}

\section{Keywords—public service; frontier; ethnic prefecture}

The Fifth Plenum of the 17th CPC Central Committee was held in Beijing from October 15 to 18, 2010. The plenum called for ensuring and improving people's livelihoods by gradually perfecting the fundamental public service system that should be working in line with relatively comprehensive, covering urban and rural areas, and sustainable development by enhancing the government's capacity for safeguarding people's livelihoods; and by promoting equal fundamental public services. Efforts should also be made to reinforce social construction and establish a fundamental public service system [1].

In the developed eastern areas of China, the local government has set up a relatively perfect social security system, but in frontier ethnic places, their public service supply capacity is weak because of their complex social environment and poor economy.

Although the central and the superior government adopted the "Western Development Strategy", "Xing Bian Fu Min" initiative and other activities to help the Yunnan local government to develop their economy, solve the problem of poverty, however the amount and the structure of public service also cannot satisfy the basic needs of local residents. Therefore, how to strengthen the ability and how to explore the effective mode of public service supply to promote the equalization of public services is still an important task faced by Local government in Yunnan.

\section{LITERATURE REVIEW}

On the one hand, ethnic areas facing the same problem with other areas in terms of public service supply mode:

Jia Lingmin, Lv Xuning [2] pointed out that the public service supply was difficult to effectively reflect the citizen's demand, the mode of public service supply was single, and there existed "dislocate" "offside" and "defaulted" phenomenon on public service supply. Low efficiency, equity and the supervision mechanism was not sound.

Zheng xiaoyan [3] focused on the government as the main supplier, pointed out that the government lack of a target and a clear overall strategy. Government had many problems like "defaulted", inefficiency and corruption.

On the other hand, due to the special environment, the ethnic areas faced different problems in public services too. Academic research was mainly from the following perspective of public management.

Wang Shengzhang [4] pointed out that Chinese financial transfer payment system, and the financial and administrative power relations between central and local government hindered the local development of public service. Ma Jianbin [5] pointed out that the administrative management system made the power dispersing, unreasonable organization and functional overlap, caused the situation of excess supply and lacking effective supply. Dang xiuyun, XinFei [6] analyzed five aspects such as the administrative environment, management ideas, performance evaluation, public finance, governance mode, he comprehensively summarized the existing problems of the public servicem. Li Dengzhou (2013) [7] used PCA(principal component analysis) to do the research of public service in eight ethnic areas such as Guangxi, Tibet provinces. He approved that Guangxi and Yunnan had best basic public services ability, Ningxia and Guizhou behind 
them, other provinces were weaker. Gao Jing [8]pointed out that because of the particularity of administrative environment, system, local demand and cost in ethnic autonomous areas, the public service faced a lot of problems, like single supplier, unreasonable structure and poor supervision system.

Innovative studies of public service system in ethnic autonomous areas, Dang xiuyun edited [9], was the representative writings in this field. The study by fieldwork analysis the social security system, public health, basic education, basic utilities in Tibet, Yunnan, Inner Mongolia, Guangxi. which attempted to make a detailed combing and analysis of the causes and problems in Chinese public service system, and put forward corresponding countermeasures.

In a word, Most research on public service supply in ethnic minority areas, mainly concentrated in only one area or the national scale. Most research was theoretical, even with quantitative research, it also stayed the data description. This study analyzed the 25 frontier ethnic counties (including nine ethnic autonomous county), through the interview method, questionnaire survey and statistical yearbook and other ways to collect data. Because respondents is remote and poor, hard to ensure the integrity of information. Relatively, input data of the local public finance expenditure is relatively reasonable, but output data is lack, the survey of public service at the county level is not easy. Therefore, according to input data, this study used PCA to build public service supply model in frontier ethnic prefectures.

In addition, the research group from January 2014 to January 2015 successively to Dehong dai and jingpo autonomous prefecture Ruili and Mangshi county, Wenshan zhuang and miao minority autonomous prefecture Funing county, Honghe hani and yi autonomous prefecture Hekou county to do research fieldwork, interviewed and collected the relevant data. Therefore, combined model analysis and interviewed data, this study summarized the basic situation of the public service in frontier ethnic prefectures, and put forward some suggestions.

\section{THE MOdEl OF PUBlic SERVICES SUPPly IN YUNNAN FRONTIER ETHNIC PREFECTURES}

\section{A. Yunnan Frontier Ethnic Areas}

Yunnan province located the southwest of China, Adjacent to Vietnam, Laos, Myanmar. It's border has $4060 \mathrm{~km}$. There are 25 in frontier counties (including nine ethnic autonomous counties), belonging to eight states, cities (including five ethnic autonomous prefectures):Baoshan city: 1, longling county. 2, tengchong(bordering with Burma). Lincang city: 1, Zhenkang county. 2,Genma yi and wa minority autonomous county. 3, Cangyuan wa minority autonomous county.(bordering with Burma) Nujiang lisu minority autonomous prefecture: 1, Gongshan dulong and nu minority autonomous county. 2, Fugong. 3, Lushui(bordering with Burma.) Dehong dai and jingppo minority autonomous prefecture: 1, mangshi 2,Ruli 3,longchuang county 4,Yinjiang county (bordering with Burma).

Honghe hani and yi autonomous prefecture: 1, Lvchun county. 2, Jinping miao yao dai minority autonomous county.
3, Hekou yao minority autonomous county (bordering with Vietnam) Wenshan zhuang and miao minority autonomous prefecture: 1,Jinghong. 2, Menghai(bordering with Burma) 3,Mwngla county(bordering with Burma and Vietnam); Puer city: 1 , Ximeng wa minority autonomous county 2 , Menglian dai lahu wa minority autonomous county 3,Lancang lahu minority autonomous county (bordering with Burma) 4,Jiangcheng hani and da i minority autonomous county(bordering with Burma and Vietnam).

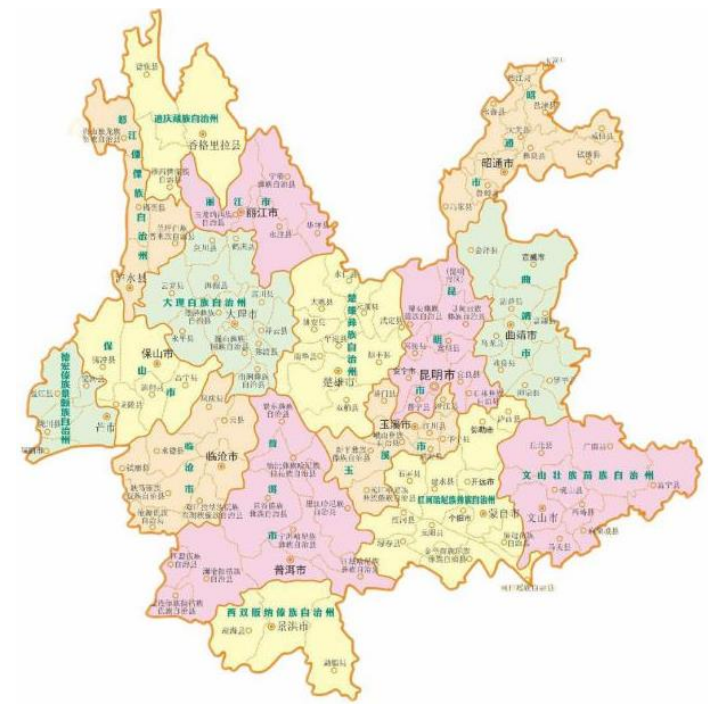

Fig. 1. Maps in Yunnan province

When writing this paper, most latest statistical data for 2015 has not been completed, the data for 2014 can not meet the requirement of the principal component analysis of KMO statistics. Therefore, in order to establish an effective model, 50 samples of 2013, 2014 had been chosen. As described earlier, the border region of Yunnan province are mostly poor, the actual output data of public service like education, health care, social security, roads, environmental protection is very hard to have an regional balance, unified time. So, it is reasonable use the input data of public service. 24 kinds of public expenditure intuitively reflect the government's investment in the public demand, indirectly reflect the key points in construction and main demand of the masses. Although the model can't reflect the overall of input and output, but generally characterizes the basic situation of the public service in the 25 frontier counties.

\section{B. Principal Component Analysis in Yunnan Frontier Ethnic Areas}

Principal component analysis is a dimension method of multivariate statistics. This method rearrange related original variable $\left(\mathrm{X}_{1}, \mathrm{X}_{2} \ldots, \mathrm{X}_{\mathrm{P}}\right)$ to generated a few unrelated principal component $\left(\mathrm{F}_{1}, \mathrm{~F}_{2}, \ldots, \mathrm{F}_{\mathrm{m}}\right)$, make as much as possible of the original information are extracted, the main contradictions have been revealed, research is simplified.

In 24 public expenditure categories, irrelevant five categories (Post-earthquake recovery expenditure, aid expenditure, reserve funds, debt servicing costs and other expenditure) and two no spending categories (Expenditure for Foreign Affairs and financial supervision) have not been 
calculated. The rest of public expenditure categories involved in modeling, in order to remove the differences in regional scale, Calculate per capita value of the remaining 17 expenditure, get a reasonable set of data $\left(\mathrm{x}_{1}, \mathrm{x}_{2}, \ldots, \mathrm{x}_{\mathrm{p}}\right)$.

It can be seen through the relevant inspection, there are a lot of significant relation $(p<0.05)$ in the 17 fiscal expenditures. each investments of public service affect each other, May be the investment increases with total investment increases, also may be these investments overlap each other. Selects the PCA can eliminate the repeated measurement of these factors, effectively measure the total effect of the 25 frontier counties. after expand the sample size, KMO test shows KMO value reached 0.769 , between 0.7 to 0.8 , to achieve the requirement of the principal component analysis.

After the PCA model is set up, standardized the average data in 25 frontier counties, then, get the data into the component model to calculate the six principal component score in 25 frontier counties. Each principal component characteristic value is used to calculate the weight of principal component, and then according to the weight combined principal component scores, the total score of 25 frontier counties are described in the appendix.

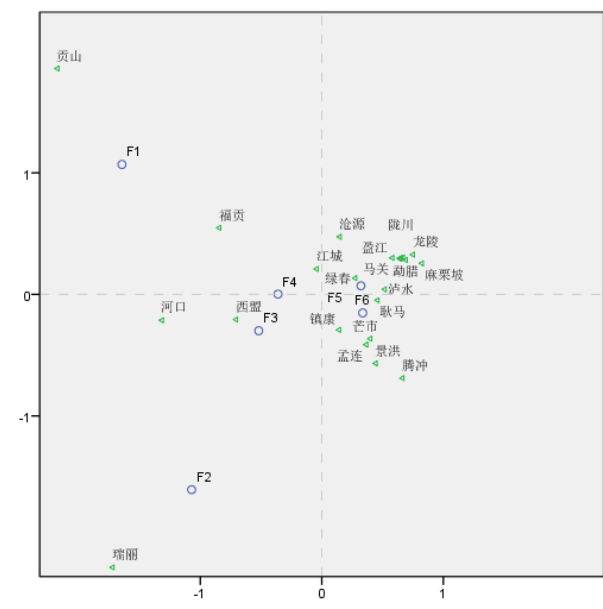

Fig. 2. The corresponding analysis diagram

\section{The BASIC Situation OF PUblic SERVICE IN FrontieR ETHNIC PREFECTURE}

It can be seen from the appendix and figure 2, F1 (the factor of construction) weights as high as 0.56 in the frontier autonomous areas. This shows the infrastructure is main demand of the public services in these areas, public services are still stay on the material stage. Compared with ranking of public service and per transfer payments in the 25 prefectures, it can be seen the public service in frontier ethnic areas are mainly affected by the natural environment and local economy. The majority of them have poor production, depend mainly on the central and provincial financial transfer payment to develop local public service.

It can be seen from the appendix, although the local GDP is low, Nujiang lisu autonomous prefecture of Gongshan dulong autonomous county relied on a large number of transfer payment to develope their own public services well, ranking first. The third Ruili, not only relying on transfer payments, and its good economic development also promoted local public service. Jinpin miao, yao dai autonomous county in Honghe hani and yi autonomous prefecture was ranking at the bottom like 25 position. This is because the economic development and transfer payment in Jinpin county are poor and not enough, difficult to guarantee the local public service.

By the league table, ethnic autonomous areas had no obvious agglomeration effect of ranking, the management of ethnic autonomous areas in Yunnan is no significant difference, autonomous advantages are not reflected.

In order to clearly understand the features of the public service in the 25 prefectures, this paper used correspondence analysis, to reduce the dimensionality of 6 scores into two-dimensional figure, and measure the degree of compliance with the distance between areas and principal component. Distance is short, the area well done on this kind of principal component, while the distance is long, the area not do well on this kind of principal component. Most areas focus on. F5 (the factor of Commercial circulation) and F6 (the factor of people's livelihood ), this shows that most of the local governments committed to develop economy, improving the living conditions and meeting the needs of people's livelihood were main responsibility for local governments.

While top places like Gongshan, hekou, Ruili, and Fugong relatively are closed with F1 (the factor of construction) and F2 (the factor of basic service), shows that the local governments not only developed economy, also heavily established construct infrastructure in order to promote the public services.

\section{SUGGESTIONS}

Based on the field survey and the conclusion of model analysis, this study proposed the following suggestions:

\section{A. Enlarging Investment from the Central Government to Enhance the Quality and Quantity of Public Service in Frontier Ethnic Prefectures}

Frontier ethnic places are located in the mountains, have poor natural conditions, backward economy and low finance supply rate. In recent years, local financial support for economic and social development is a heavy task, getting a wide range of financial security, and the demand of financial expenditure is growing faster than the growth of financial revenue. Therefore, in order to promote the border stability, ethnic harmony, the international demonstration effect, this study suggested that the government should increase investment in the central government, improve the border subsidies, implement preferential policies in frontier minority areas to support local education, health care, social security and other public service, and comprehensively improve the basic public service level.

\section{B. Expending Investment in Transportation Infrastructure, Attaches Importance to Frontier Highway Construction}

The central government should increase investment in infrastructure construction in border areas by adopting active 
investment policy to accelerate the pace of construction of frontier area and to encourage people to move to the border areas. Therefore, this study suggested that the central government should increase investment in traffic construction to improve the road network. At the same time, strengthening frontier highway construction is helpful for national defense and economic development.

\section{Focusing on the Construction of E-government to Promote the "one-stop" Services}

Local autonomous government should establish online information exchange system and build a network with the state government website as the center and the public as a target of "one-stop" government services. By doing so, to improve local government efficiency and effectiveness of public service.

\section{Implementing Preferential Education Policies}

This study suggested that China should deepen the reform of personnel system in frontier ethnic prefecture, to improve teachers' status, increase school subsidies, and make special allowance funds for local teachers.

\section{E. Increasing the Financial Investment in Health Care}

The central government should implement preferential policies to improve the quality of local health care professionals, and make special policies to attract excellent medical talent service in frontier ethnic prefecture. Also, local government should accelerate the internationalization process of medical and health services in frontier ethnic prefecture.

\section{F. Strengthening the Cooperation of the Government Authorities}

This study suggested that central government should increase the financial investment to social security in frontier ethnic prefecture, expand the coverage of the social security system. Local authorities like social security, civil affairs, relief stations, public security, urban management, public health, and transportation bureau should actively fulfill their own responsibilities and to build collectively a sound social security system.

\section{CONCLUSIONS}

Frontier ethnic prefectures are mostly located in remote areas, they have poor natural conditions and economy, which make the public service supply a series of problems. It is particularly important to effectively enhance the public services and build effective supply mechanism of public service. Based on statistical data of public service in Yunnan 25 frontier of ethnic prefecture, and research fieldworks in Funing. Hekou、 Ruili、 Mangshi, this research found that, under the financial support from central government and Yunnan local government, a basic social security system has been established in those frontier ethnic areas, and compulsory education, public health, traffic infrastructure have been developed to some extent. But the supply autonomy, and ethnicity is not apparent character during public service provision, economic development is still a key duty for local government in Yunnan. Therefore, this study suggested that, in order to enhance the quality and quantity of public service in frontier of ethnic prefecture, Chinese central government should provide more funding for local public service, make series of priority policies to improve the development of education and public health, and strengthen the cooperation between various local authorities to build a sound social security system.

\section{ACKNOWLEDGMENT}

This article comes from a fund project which is the ministry of education humanities and social sciences general research project (13 yja630096). And the authors all belong to Yunnan University of finance and economics.

\section{REFERENCES}

[1] Bulletin of the fifth plenary session of the 17th communist party of China.[EB/OL]http://baike.baidu.com/link?url=RAYZAQKnr42syzQkg -Vy1-MSj4RHxS1B7POScxQ4TJJegbOW5WbOWokcNAFMb5rHcJfg FzkU83LV4gZOlHcFIK

[2] Jia Lingmin, Lv Xuning. Study on public service supply mode innovation [J]. Journal of Chinese administrative management, 2007 (4) 22-24. (In Chinese)

[3] Zhen Xiaoyan. The research on development of Chinese public service supply subject [D]. Wuhan: east China normal university, 2010.(In Chinese)

[4] Wang Shengzhang. Current influence national white put barriers and countermeasures for the construction of public service system of local government [J]. Journal of yunnan normal study, 2006 (3) : 40-44.(In Chinese)

[5] Ma Jianbin. Growth and service:the national autonomous local government constructing public service oriented government of double troubles and path selection [J]. Market BBS, 2008 (3) : 8-10(In Chinese)

[6] Dang Xiuyun, XinFei. Ethnic minority areas in the new period of public service management are faced with the problem and strategy selection $[\mathrm{J}]$. Journal of central university for nationalities (philosophy and social sciences edition), 2010, 5 (6) : 34-38.(In Chinese)

[7] Li Dengzhou.National eight provinces comparative study of the public service ability. Anhui administrative college journal. 2013. 02(In Chinese)

[8] Gao Jing.Local public service supply mechanism in regional national autonomy areas. Master thesis, Inner Mongolia university. 2012.05(In Chinese)

[9] Dang Xiuyun. Local public service system innovation in national autonomy areas. People's publishing house. 2009(In Chinese) 


\section{APPENDIX}

Public Service Level in Yunnan Frontier Ethnic Prefectures

\begin{tabular}{|c|c|c|c|c|c|c|c|c|c|c|c|}
\hline \multirow[b]{2}{*}{ state/city } & \multirow[b]{2}{*}{ county/city } & \multirow{2}{*}{$\begin{array}{c}\text { Rankin } \\
\text { g of per } \\
\text { transfe } \\
r \\
\text { payme } \\
\text { nts }\end{array}$} & \multirow{2}{*}{$\begin{array}{c}\text { per } \\
\text { transfer } \\
\text { payment } \\
\text { s (yuan) }\end{array}$} & \multirow{2}{*}{$\begin{array}{c}\text { Comp } \\
\text { rehen } \\
\text { sive } \\
\text { rakin } \\
\text { g }\end{array}$} & \multirow[t]{2}{*}{ weight } & \multirow{2}{*}{$\begin{array}{c}0.56 \\
\mathbf{F 1}\end{array}$} & \multirow{2}{*}{$\begin{array}{r}0.14 \\
\text { F2 }\end{array}$} & \multirow{2}{*}{$\begin{array}{r}0.09 \\
\text { F3 }\end{array}$} & \multirow{2}{*}{$\begin{array}{r}0.08 \\
\mathbf{F 4}\end{array}$} & \multirow{2}{*}{$\begin{array}{r}0.07 \\
\mathbf{F 5}\end{array}$} & \multirow{2}{*}{$\begin{array}{r}0.06 \\
\text { F6 }\end{array}$} \\
\hline & & & & & & & & & & & \\
\hline Nujiang & Gongshan* & 1 & 20748 & 1 & 6.30 & 11.98 & -1.34 & -1.15 & -1.83 & 0.22 & 0.30 \\
\hline Honghe & Hekou* & 3 & 9399 & 2 & 2.17 & 3.32 & 1.17 & 1.65 & 1.93 & -1.90 & -0.41 \\
\hline Dehong & Ruili & 9 & 7238 & 3 & 1.80 & 1.94 & 5.59 & 0.86 & -0.88 & -0.75 & -0.73 \\
\hline Nujiang & Fugong & 2 & 10564 & 4 & 1.31 & 2.39 & -2.32 & 2.59 & 1.17 & 0.10 & -0.42 \\
\hline Puer & Ximeng* & 5 & 9127 & 5 & 1.26 & 2.12 & 1.06 & -2.76 & 1.61 & 0.46 & 0.25 \\
\hline Lincang & Cangyuan* & 6 & 8408 & 6 & 0.84 & 1.40 & -0.99 & 0.63 & 0.56 & 0.30 & 1.25 \\
\hline Lincang & Zhenkang & 7 & 8127 & 7 & 0.68 & 0.74 & 0.64 & 1.30 & -0.67 & 1.17 & 0.49 \\
\hline Puer & Jiangcheng* & 4 & 9299 & 8 & 0.54 & 0.90 & 0.33 & -0.84 & 1.47 & -0.28 & -0.49 \\
\hline Nujiang & Lushui & 11 & 6893 & 9 & 0.30 & 0.24 & 0.22 & 0.36 & 0.36 & 0.18 & 0.89 \\
\hline Honghe & Lvchun & 10 & 6895 & 10 & -0.44 & -0.86 & -0.98 & 1.36 & 1.27 & 0.03 & -0.68 \\
\hline Puer & Menlian* & 8 & 7295 & 11 & -0.45 & -0.74 & 0.73 & -0.66 & 0.02 & -0.39 & -0.92 \\
\hline $\begin{array}{l}\text { Xishuangban } \\
\text { na }\end{array}$ & Jinghong & 25 & 3668 & 12 & -0.55 & -1.27 & 0.81 & -1.09 & 0.85 & -0.37 & 1.60 \\
\hline Baoshan & Longlin & 14 & 5815 & 13 & -0.65 & -0.83 & -0.64 & -0.72 & -0.84 & 0.77 & -0.35 \\
\hline Wenshan & Malipo & 15 & 5445 & 14 & -0.66 & -1.40 & -0.20 & 0.29 & 0.11 & 1.09 & 0.81 \\
\hline Lincang & Genma* & 16 & 5275 & 15 & -0.66 & -1.26 & 0.08 & 1.58 & -1.73 & -0.48 & 0.84 \\
\hline Dehong & Yinjiang & 12 & 6544 & 16 & -0.74 & -0.71 & -1.22 & -0.60 & -0.50 & 0.03 & -1.26 \\
\hline Dehong & Longchuag & 13 & 6006 & 17 & -0.77 & -0.93 & -0.28 & -0.95 & -0.58 & 0.08 & -1.36 \\
\hline Baoshan & Tengchong & 24 & 3700 & 18 & -0.94 & -2.44 & 0.95 & 0.21 & 0.61 & 1.18 & 2.42 \\
\hline Wenshan & Maguan & 22 & 4472 & 19 & -1.14 & -1.91 & -0.98 & 0.07 & 0.93 & 0.29 & -0.44 \\
\hline $\begin{array}{l}\text { Xishuangban } \\
\text { na }\end{array}$ & Mengla & 18 & 5124 & 20 & -1.14 & -1.75 & -1.01 & 0.04 & -0.67 & 0.21 & 0.24 \\
\hline $\begin{array}{l}\text { Xishuangban } \\
\text { na }\end{array}$ & Menghai & 20 & 4861 & 21 & -1.29 & -1.95 & -0.43 & -0.22 & -0.53 & 0.03 & -1.26 \\
\hline Puer & Lancang* & 17 & 5199 & 22 & -1.32 & -1.83 & -0.74 & -0.74 & -0.35 & -1.47 & 0.02 \\
\hline Wenshan & Funing & 19 & 4928 & 23 & -1.37 & -1.89 & -1.07 & -0.58 & -0.97 & 0.19 & -0.83 \\
\hline Dehong & Mangshi & 23 & 3863 & 24 & -1.47 & -2.57 & 0.67 & -0.46 & -0.63 & -0.53 & 0.04 \\
\hline Honghe & Jinpin* & 21 & 4811 & 25 & -1.60 & -2.70 & -0.05 & -0.16 & -0.71 & -0.14 & -0.01 \\
\hline
\end{tabular}

Note: * for border ethnic autonomous counties, data from the statistics bulletin of the national economy and social development2013,2014, Yunnan statistical yearbook 2014,2015, local fiscal budget execution2013,2014, the local government report 20142015 